\title{
Differential UCS expectancy bias in spider fearful individuals: evidence toward an association between spiders and disgust-relevant outcomes
}

Citation for published version (APA):

van Overveld, M., de Jong, P. J. ., \& Peters, M. L. (2006). Differential UCS expectancy bias in spider fearful individuals: evidence toward an association between spiders and disgust-relevant outcomes. Journal of Behavior Therapy and Experimental Psychiatry, 37, 60-72.

https://doi.org/10.1016/j.jbtep.2005.09.007

Document status and date:

Published: 01/01/2006

DOI:

10.1016/j.jbtep.2005.09.007

Document Version:

Publisher's PDF, also known as Version of record

Document license:

Taverne

Please check the document version of this publication:

- A submitted manuscript is the version of the article upon submission and before peer-review. There can be important differences between the submitted version and the official published version of record.

People interested in the research are advised to contact the author for the final version of the publication, or visit the DOI to the publisher's website.

- The final author version and the galley proof are versions of the publication after peer review.

- The final published version features the final layout of the paper including the volume, issue and page numbers.

Link to publication

\footnotetext{
General rights rights.

- You may freely distribute the URL identifying the publication in the public portal. please follow below link for the End User Agreement:

www.umlib.nl/taverne-license

Take down policy

If you believe that this document breaches copyright please contact us at:

repository@maastrichtuniversity.nl

providing details and we will investigate your claim.
}

Copyright and moral rights for the publications made accessible in the public portal are retained by the authors and/or other copyright owners and it is a condition of accessing publications that users recognise and abide by the legal requirements associated with these

- Users may download and print one copy of any publication from the public portal for the purpose of private study or research.

- You may not further distribute the material or use it for any profit-making activity or commercial gain

If the publication is distributed under the terms of Article $25 \mathrm{fa}$ of the Dutch Copyright Act, indicated by the "Taverne" license above, 


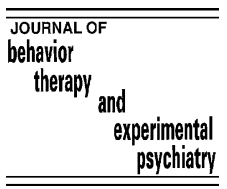

\title{
Differential UCS expectancy bias in spider fearful individuals: Evidence toward an association between spiders and disgust-relevant outcomes
}

\author{
Mark van Overveld ${ }^{\mathrm{a}, *}$, Peter J. de Jong ${ }^{\mathrm{b}}$, Madelon L. Peters ${ }^{\mathrm{a}}$ \\ ${ }^{a}$ Department of Medical, Clinical, and Experimental Psychology, Maastricht University, P.O. Box 616, \\ 6200 MD Maastricht, The Netherlands \\ ${ }^{\mathrm{b}}$ Department of Clinical and Developmental Psychology, University of Groningen, The Netherlands
}

\begin{abstract}
Recently, differential UCS expectancies were found for high- and low-predatory fear-relevant animals [Davey, G. C. L., Cavanagh, K., \& Lamb, A. (2003). Differential aversive outcome expectancies for high- and low-predation fear-relevant animals. Journal of Behavior Therapy and Experimental Psychiatry, 34, 117-128]. The present study extends these findings to spider phobia. In a hypothetical experiment, high $(n=27)$ and low $(n=28)$ spider fearful individuals estimated the probability that slides of spiders, maggots, pit bull terriers, or rabbits would be followed by a sip of nauseating juice, a shock, or nothing. Maggots were selectively associated with the disgusting juice, pit bull terriers with the harm-related shock, and rabbits with nothing. Spiders were associated with both aversive UCSs, but significantly stronger in the high fear group. Additionally, an expectancy bias toward disgust-relevant consequences was the single best predictor of spider fear. These findings imply that in accordance with the disease-avoidance model, expectations of disgust-relevant consequences are involved in spider phobia.
\end{abstract}

(C) 2005 Elsevier Ltd. All rights reserved.

Keywords: Disgust; UCS expectancy bias; Spider fear

\footnotetext{
*Corresponding author. Tel.: + 3143 3881608; fax: + 31433884155

E-mail addresses: M.vanOverveld@DMKEP.Unimaas.nl (M. van Overveld), p.j.de.jong@rug.nl (P.J. de Jong), madelon.peters@dep.unimaas.nl (M.L. Peters).
} 


\section{Introduction}

There is considerable evidence that phobic individuals have a tendency to over-associate encounters with phobic stimuli with the occurrence of aversive consequences (e.g., Davey, 1992a; Tomarken, Mineka, \& Cook, 1989). Thus, upon confrontation with their phobic objects, fearful individuals expect an aversive consequence to occur. Accordingly, it has been shown under laboratory conditions that phobic individuals display inflated expectancies that aversive consequences, e.g., electrical shocks, will follow fear-relevant stimuli. This has been found in different kinds of anxiety disorders, such as snake phobia (McNally \& Heatherton, 1993), flight phobia (Pauli, Wiedemann, \& Montoya, 1998), and panic disorder (Wiedemann, Pauli, \& Dengler, 2001). Such bias logically acts in a way that contributes to the continuation and heightening of fear.

Expectancy bias seems also involved in spider phobia. In a 'thought' experiment procedure, spider phobics reported higher expectations of an aversive outcome (electrical shock) to follow the occurrence of spider stimuli than non-phobics (Cavanagh \& Davey, 2000; Öhman, Dimberg, \& Öst, 1985). Moreover, when actually exposed to a random combination of slides (snakes, spiders, electrical outlets, flowers) and outcomes (shock, tone, or nothing), specifically high spider fearful participants overestimated the covariation between spiders and the occurrence of aversive outcomes (shock) (Kennedy, Rapee, \& Mazurski, 1997).

The expectation that aversive, harm-related consequences will follow upon the presentation of spider slides is consistent with the predator-defense model. This model postulates that a fear of small animals is derived from defensive strategies, which have developed as a result of the threat of predators (Öhman et al., 1985). Spiders and snakes would thus be feared due to their harmful, predatory properties. Yet, there is accumulating evidence that not only threat-related beliefs contribute to a fear of spiders, but also disgustrelated preoccupation with the spider (Sawchuk, Lohr, Tolin, Lee, \& Kleinknecht, 2000; Tolin, Lohr, Sawchuk, \& Lee, 1997). Accordingly, when viewing spider slides, spider phobics not only report feelings of fear, but also feelings of disgust (Sawchuk, Lohr, Westendorf, Meunier, \& Tolin, 2002; Tolin et al., 1997). In addition, spider phobics report that spiders are not only their most feared objects, but they are also the ones they find most disgusting (Thorpe \& Salkovskis, 1998). Also, when confronted with spiders, highly spider fearful people respond with greater disgust-specific facial EMG activity, i.e., activity of the m. levator labii than explicitly non-fearful people (de Jong, Peters, \& Vanderhallen, 2002). Underlining the relative importance of disgust-related convictions, recent research has shown that fear of being contaminated with a disgusting object (a spider) is a better predictor of spider fear than the fear of physical harm (de Jong \& Muris, 2002). All of these findings are consistent with the disease-avoidance model, which states that a fear of harmless, small animals is not the result of expecting harm from a confrontation with these animals, but rather originates from a fear of contamination with dirt or disease (Matchett \& Davey, 1991).

So far, research on expectancy bias has almost exclusively focused on expectations of harm-related consequences (e.g., an electrical shock) while according to the diseaseavoidance model, disgust-related outcomes might provide a more likely explanation of spider phobia. Germane to this, it has been shown that outcome expectancies vary depending on the type of CS that is presented (Davey, Cavanagh, \& Lamb, 2003). That is, in a 'thought' experiment, participants were asked to rate the probability that slides of 
different kinds of animals would be followed by one of the three consequences, namely by an electrical shock, a sip of a disgusting drink, or no response at all. Three types of animals were used in this experiment: low-predatory fear-relevant animals (spider, maggot, cockroach, slug), high-predatory fear-relevant animals (tiger, wolf, shark, snake), and safe fear-irrelevant animals (rabbit, kitten, sheep, chicken). Results indicated that the fearrelevant high-predatory animals were selectively associated with the harm-related consequence (shock) and fear-relevant but low-predatory animals with the disgust consequence (nauseating drink). Neutral animals were associated with neither shock nor drink (Davey et al., 2003). Most important for the present context is that the lowpredatory fear-relevant animals in that study were associated with a disgusting outcome, and not with a harm-related consequence (shock). The present study has elaborated on these findings on the existence of differential UCS expectancies for various animal types, and extended them to spider phobia.

Therefore, the major goal of the present study was to examine the relative importance of disgust and harm-related expectancies in spider fear. As mentioned above, spiders may be feared due to relatively strong harm-related outcome expectancies (predator-defense model) or relatively inflated UCS disgust representations (as would be predicted by the disease-avoidance conceptualization of spider phobia) or by both. To investigate these issues, a group of high spider fearful individuals and a group of low spider fearful individuals were asked to participate in a hypothetical aversive conditioning experiment. They had to estimate the probability that pictures of spiders, maggots, pit bull terriers, or rabbits would be followed by one of the three outcomes: (a) insertion of a sip of nauseating juice in the mouth via a catheter, (b) administration of a painful electrical shock, or (c) nothing at all.

In conclusion, the present study was designed to test: (1) the robustness of the earlier finding of Davey et al. (2003) that differential UCS expectancies can be found in individuals, independent of prior fear; (2) the prediction that, in line with previous research (de Jong \& Muris, 2002; Tolin et al., 1997), spiders will not only be associated with harm, but also with disgust-related consequences; (3) the hypothesis that, in accordance with previous research (de Jong \& Muris, 2002), high spider fearful participants will associate spiders more strongly with both aversive consequences, yet, disgust-related convictions will differentiate best between high and low spider fearful groups. In other words, high spider fearful people will be characterized by a stronger disgust-related preoccupation with spiders compared to low spider fearful people.

\section{Methods}

\subsection{Participants}

Participants were selected from a large sample of Dutch students at the Faculties of Health Science, Medicine, and Psychology at the University of Maastricht $(N=359)$. They were selected on the basis of their spider fear rating on a Visual Analog Scale ranging from 0 (no fear at all) to 100 (extremely fearful). The 35 lowest scoring individuals (VAS $<11$ ) were invited for the final screening, as well as the 35 persons with the highest scores (VAS > 77). The final decision to include participants in either the low spider fear group or the high spider fear group was made on the basis of their scores on the Fear of Spiders Questionnaire (FSQ) (see below). A total of 55 persons agreed to participate, of 
whom 27 were assigned to the low fear group, and 28 to the high fear group. Since the prevalence of spider phobia is much higher in women than in men (Davey, 1997), only women were selected to participate. The mean age was 19.1 years $(\mathrm{SD}=1.5)$ in the low fear group and 18.7 years $(\mathrm{SD}=0.8)$.

\subsection{Materials}

\subsubsection{Fear of Spiders Questionnaire}

The FSQ is a questionnaire measuring fear of spiders. Participants rate 18 items on an eight-point Likert-type scale, ranging from 0 to 7 . Items assess how strongly people tend to avoid spiders, and how anxious they become when encountering a spider (e.g., "If I came across a spider now, I would get help from someone else to remove it"). The FSQ has good psychometric properties. It is known to have a high internal consistency $(\alpha=0.92)$ (Szymanski \& O’Donohue, 1995) as well as high test-retest reliability (0.91) (Muris \& Merckelbach, 1996). The FSQ has a range of 0-126. The FSQ was used to make the final decision to assign a subject to either the high spider fear group (FSQ $>30$ ) or the low spider fear group $(\mathrm{FSQ}<30)$. There was an average score of 5.48 on the FSQ (SD = 7.28) in the low spider fear group, and an average score of $65.54(\mathrm{SD}=19.13)$ in the high spider fear group. The mean of the high spider fear group is comparable with previous studies using analog, non-clinical samples $(M=62.3, \mathrm{SD}=21.6$; de Jong et al., 2002; $M=61.7$, $\mathrm{SD}=25.6$; Woody \& Tolin, 2002), but are clearly lower than studies using clinical samples $(M=89.1, \mathrm{SD}=19.6$; Muris \& Merckelbach, 1996).

\subsubsection{UCS expectancies}

Participants were presented with a verbal description of the experiment, after which they filled in the questionnaire. The instruction was as follows:

\section{Thought experiment}

This brief questionnaire studies how people perceive experimental research. This will be done by studying beliefs about certain animals.

\section{Description of the experiment}

You are about to participate in a thought experiment. This means that we will ask you to imagine as vividly as possible the following situation. You are invited here to participate in an experimental study at the laboratory. You will be asked to sit down in a comfortable chair, and view a series of slides, projected on the large screen in the lab. Two electrodes will be placed on your upper arm and before the experiment starts a level of electrical shock will be selected in consultation with you. This will be done so the level is certainly unpleasant, yet not painful. During the experiment you will receive shocks at certain moments. Also, a catheter will be inserted in your mouth, and taped to your cheek, so at certain moments a fluid can be injected. This fluid will taste very bitter, and is quite nauseating. The fluid is, however, just like the shock, unpleasant yet harmless and without side effects.

During the experiments you will be shown a series of slides of four types of animals: pit bull terriers, spiders, maggots, and rabbits (at this point, some exemplary slides were shown of a growling pit bull terrier, a spider, maggots, and a white rabbit). Each slide will be shown for exactly $6 \mathrm{~s}$ and will immediately be followed by one of these three consequences: either you will receive a short but unpleasant electrical shock, or 
a shot of the nauseating, bitter fluid will be injected into your mouth, or nothing will happen.

Now imagine you are seated in the chair, with the electrodes attached to your right upper arm and the catheter inserted in your mouth. The light is waning and the first slide will soon appear on the screen. You may now fill in the questionnaire.

The thought experiment itself consisted of a questionnaire on which participants had to make UCS expectancy judgments of the association between slides of certain animals and one of the three possible consequences: injection into the mouth of a nauseating but harmless drink (disgust-related outcome), an unpleasant but not painful electric shock (harm-related outcome), or no response at all. The animals were divided into three categories: high-predatory animals (pit bull terriers), low-predatory, high-disgusting animals (maggots), and neutral animals (rabbits). Spiders were included as an additional category to examine whether different UCS expectancies would be observed between the high spider fearful group and the low spider fearful group.

For each of the slides, it had to be rated how many of these slides were to be followed by the drink, the shock, or by nothing on a $100 \mathrm{~mm}$ VAS, ranging from 0 ('none at all') to 100 ('all'). Thus, a total of 12 UCS expectancy judgments were obtained (4 animals $\times 3$ consequences). The sequence of these outcome ratings was fixed in a random order. First, participants had to rate the chance that slides of four animals (in this order: pit bull terriers, spiders, maggots, and rabbits) were followed by an electrical shock. Next, ratings had to be given for the disgusting consequence, and finally, for expecting nothing. At the end of the questionnaire, participants also rated their fear of each of the four types of animals on a VAS scale ranging from 0 ('not afraid at all') to 100 ('very afraid').

\subsubsection{Procedure}

On arrival at the lab, participants completed the Dutch translation of the FSQ. Next, the experimenter read aloud the introduction to the 'thought experiment' questionnaire, and showed one exemplary slide for each animal, after which the participants had to complete the questionnaire. Afterward, they received a small reward for participating in the experiment.

\section{Results}

\subsection{Data reduction and analysis}

To test the hypothesis that differential UCS expectations exist for pit bull terriers, maggots, and rabbits, expectancy ratings were subjected to a 3 (Animal Type: pit bull terriers, maggots, rabbits) $\times 2$ (Outcome: harm-related consequence, disgust-related consequence) $\times 2$ (Spider Fear: high and low) ANOVA. Comparisons were made for the variable Outcome, in which the expectation of nothing was subtracted from the expectation of an aversive consequence (harm-related: expectation of shock minus expectation of nothing; disgust-related: expectation of juice minus expectation of nothing).

Next, a series of post hoc $t$-tests was conducted in order to specify which consequence was associated most strongly with each of the animals. For each animal, three $t$-tests were performed that compared the expectation of shock versus nothing, juice versus nothing and shock versus juice. 
Finally, a regression analysis was used to study the relative contributions of the expectations of juice and shock to the fear of the three animals (pit bull terriers, maggots, and spiders). A VAS scale on animal fear (i.e., fear of pit bull terriers, maggots, or spiders) was used as the dependent and both UCS expectancies (shock and juice) as the predictor variables.

\subsection{UCS expectations for pit bulls, maggots, and rabbits}

The 3 (Animal Type: pit bull terriers, maggots, rabbits) $\times 2$ (Outcome: shock minus nothing, juice minus nothing) $\times 2$ (Spider Fear: high and low) ANOVA revealed a main effect for Animal Type $[F(2,52)=79.94 ; p<0.01 ; d=0.75]$. This means that there was a difference between the animals to which they were associated with either of the aversive consequences. This is displayed in Fig. 1a, which clearly shows that participants expected an aversive consequence to follow after the presentation of pit bulls and maggots but not after the slides of rabbits. The main effect for Outcome did not reach significance $[F(1$, $53)=2.99 ; p=0.09 ; d=0.53]$, indicating that, independent of animal type, both groups expected the aversive consequences (shock and juice) to occur equally often.

The crucial Animal Type by Outcome interaction was significant $[F(2,52)=29.01$; $p<0.01 ; d=0.53]$ which means that differential UCS expectations existed for the animals in this study. There was no significant Animal Type by Outcome by Spider Fear interaction $[F(2,52)=1.25 ; p=0.30 ; d=0.05]$, indicating that this differential pattern of
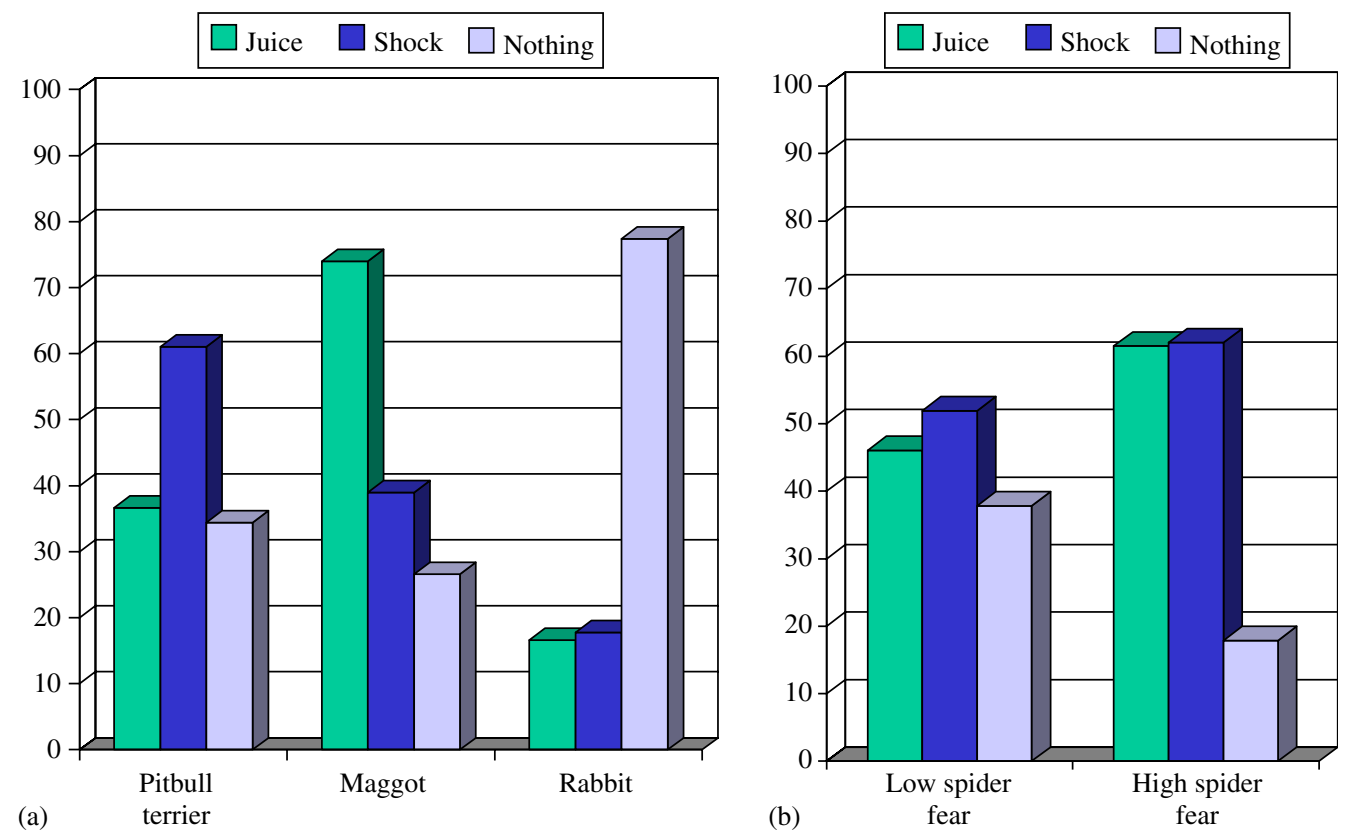

Fig. 1. Outcome expectancies for all animals: (a) depicts UCS expectancies (juice, shock, nothing) for all animals (pit bull terriers, maggots, rabbits) for the low and high fear groups together, since no differences were observed between the two groups and (b) depicts UCS expectancies (disgusting juice minus nothing, painful shock minus nothing) for the phobic object (spiders) for the low and high spider fear groups. 
associations was the same for low and high spider fear participants. In addition, none of the other interactions with spider fear, nor the spider fear main effect $[F(1,53)=0.00$; $p<0.95 ; d=0.00]$ reached significance. This indicates that there were no significant differences in UCS expectations for the three animals between low and high spider fearful individuals.

Subsequently, a series of post hoc one-sample $t$-tests were performed, revealing that pit bull terriers were significantly more strongly associated with the expectation of the shock compared to the expectations of the juice $[t=6.88 ; p<0.01]$ or with no consequence $[t=7.51 ; p<0.01]$. For the pit bull terriers, no differences were observed between expectations of the juice and no consequence $[t=0.69 ; p=0.49]$. Maggots were significantly more strongly associated with the juice compared to the shock $[t=11.27$; $p<0.01]$ or with expectations of nothing $[t=15.25 ; p<0.01]$. Participants also expected a shock significantly more often than nothing after presentation of maggots $[t=3.62$; $p<0.01]$. After the presentation of the rabbit, nothing was expected to occur significantly more often than either the shock $[t=-4.31 ; p<0.01]$ or the juice $[t=-16.51 ; p<0.01]$. The expectation of the juice and the expectation of the shock did not differ significantly after presentation of a rabbit $[t=-0.46 ; p<0.65]$.

\subsection{UCS expectations for spiders}

A 2 (Outcome: shock minus nothing, juice minus nothing) $\times 2$ (Spider Fear: high-fear, low-fear group) ANOVA was performed to examine whether the two groups differed in their UCS expectations after hypothetical presentation of a spider slide. The intercept of this analysis was significant $[F(1,53)=35.04 ; p<0.01 ; d=0.40]$, which indicates that, in general, people expect an aversive consequence to occur with greater probability than a neutral consequence after the presentation of a spider slide. The strengths of the expectations of the aversive juice and the aversive shock were similar. There was no main effect of Outcome $[F(1,53)=0.79 ; p<0.38 ; d=0.02]$. Most important for the present context, results did reveal a significant difference in the between-groups factor Spider Fear $[F(1,53)=12.56 ; p<0.01 ; d=0.19]$. This shows that although both groups expected an aversive consequence after imaginary presentation of a spider, this expectation was especially pronounced in the high spider fearful group. The inflated expectations in the high spider fear group were similar for both consequences, as was evidenced by the absence of a significant Outcome by Spider Fear interaction $[F(1,53)=0.30 ; p<0.59 ; d=0.01]$.

\subsection{UCS expectations and contributions to animal fear}

Regression analyses were used to study the relative contributions of expectations of juice and shock to fear of the three animals (pit bull terriers, maggots, and spiders). In the regression analyses, animal fear (i.e., fear of pit bull terriers, maggots, or spiders), as indexed by the VAS scales, was used as the dependent and both UCS expectancies (shock and juice) as the predictor variables. Table 1 summarizes the results of the regression analyses. The analyses indicated that with respect to fear of pit bull terriers, the single best predictor was the expectation of a harm-related consequence $(\beta=0.30 ; p=0.03)$, while the disgust expectancy was irrelevant $(\beta=0.02 ; p=0.88)$. A second analysis indicated that a fear of maggots was not predicted by expectations of either harm-related consequences $(\beta=-0.03 ; p=0.82)$ or disgust-related consequences $(\beta=0.05 ; p=0.74)$. For spider 
Table 1

Summary of the regression analyses for UCS expectations and prediction of animal fear

\begin{tabular}{lrc}
\hline & $\beta$ & $p$ \\
\hline Spider fear: $R^{2}=0.15, p=0.02$ & & \\
$\quad$ Juice & 0.296 & 0.03 \\
Shock & 0.172 & 0.21 \\
Pit bull terrier fear: $R^{2}=0.09, p=0.08$ & & \\
$\quad$ Juice & 0.021 & 0.88 \\
Shock & 0.302 & 0.03 \\
Maggot fear: $R^{2}<0.01, p=0.92$ & & \\
$\quad$ Juice & 0.046 & 0.74 \\
Shock & -0.033 & 0.82 \\
Rabbit fear: $R^{2}=0.06, p=0.20$ & & \\
$\quad$ Juice & 0.332 & 0.21 \\
Shock & -0.110 & 0.68 \\
\hline
\end{tabular}

Table 2

Summary of bivariate Pearson's $p-m$ correlations for animal fear and UCS expectations

\begin{tabular}{|c|c|c|c|c|}
\hline & Fear of pit bulls & Fear of maggots & Fear of rabbits & Fear of spiders \\
\hline \multicolumn{5}{|c|}{ Expectation of shock } \\
\hline$r$ & $0.30^{*}$ & -0.04 & 0.18 & 0.27 \\
\hline$p$ & 0.03 & 0.80 & 0.20 & 0.05 \\
\hline \multicolumn{5}{|c|}{ Expectation of juice } \\
\hline$r$ & 0.03 & 0.05 & 0.24 & $0.35^{* *}$ \\
\hline$p$ & 0.84 & 0.73 & 0.08 & $<0.01$ \\
\hline \multicolumn{5}{|c|}{ Expectation of nothing } \\
\hline$r$ & -0.24 & $-0.34^{*}$ & -0.07 & $-0.43 * *$ \\
\hline$p$ & 0.08 & 0.01 & 0.62 & $<0.01$ \\
\hline
\end{tabular}

**Is significant at the 0.01 level (two tailed).

*Is significant at the 0.05 level (two tailed).

fear, the single best predictor was the expectation of a disgusting response (juice) after presentation of spider slides $(\beta=0.29 ; p=0.03)$. Shock expectancies had no independent predictive properties $(\beta=0.17 ; p=0.21)$.

A series of bivariate correlations were conducted, to examine whether the fear of each animal (as measured with a VAS scale) was significantly correlated with certain UCS expectations (either the expectation of juice minus nothing or shock minus nothing). The results are displayed in Table 2. Significant correlations were observed between fear of pit bull terriers and the expectation of shock $(r=0.30 ; p=0.03)$, and between fear of spiders and the expectation of juice $(r=0.35 ; p<0.01)$. The correlation between spiders and the expectation of the shock approached significance $(r=0.27 ; p=0.05)$. The spiders were significantly negatively correlated with the expectation of no consequence $(r=-0.43$; $p<0.01$ ), indicating that the more fearful the participants were of spiders, the more they expected one of the aversive consequences. The same inverse correlation was found 
between the maggots and expectations of no consequence $(r=-0.34 ; p=0.01)$. Fear of maggots was not significantly correlated with expectations of any aversive consequence, indicating that people who are more fearful of maggots do not necessarily expect a specific consequence to occur. Rabbits were not significantly associated with any consequence.

\section{Discussion}

The major findings can be summarized as follows: First, evidence was found for differential UCS expectations for different animals. More specifically, participants selectively associated a pit bull terrier (high-predatory animal) with a harm-related consequence, a maggot (high-disgusting animal) with a disgusting consequence and a rabbit (neutral animal) with no consequence; Second, spiders were associated with aversive consequences (shock and juice) in both the low and high spider fearful groups; Third, although both groups expected an aversive consequence following a spider, the high spider fearful group expected significantly more often that either of the aversive consequences would occur; Fourth, finally, the single best predictor of a fear of spiders was the expectation of a disgusting consequence, while the single best predictor of a fear of pit bull terriers was the expectation of harm-related consequences.

In line with previous research (Davey et al., 2003), the present data add to the evidence that differential UCS expectancies exist for various groups of animals. The major goal of the present study was to investigate to what extent the expectations of disgust- and harmrelated consequences are implicated in spider fear. In spider phobics, an expectancy bias has been found for the expectation of harm-related consequences (Cavanagh \& Davey, 2000; Kennedy et al., 1997; Öhman et al., 1985). However, based on the accumulating evidence that the emotion of disgust contributes significantly to the existence and maintenance of spider phobia, the possibility arises that an expectancy bias toward disgusting consequences might also be relevant. Data from the present study reveal that the spiders were indeed associated with both aversive consequences (shock and juice) in both the high and low spider fearful groups, but significantly more strongly in the high spider fearful group. This evidence is in line with previous research, showing that spider phobics associate spiders with both harm-related and disgusting qualities (Davey, 1992b; de Jong \& Muris, 2002; Thorpe \& Salkovskis, 1998).

In addition, it was also studied which of the consequences would contribute most to spider fear. The data revealed that the expectation of a disgusting consequence was the strongest predictor of spider fear. Thus, results of this study are consistent with previous research (de Jong \& Muris, 2002; de Jong et al., 2002), which found that the perceived probability of involuntary physical contact with a disgusting object is a better predictor of spider fear than the perceived probability of being attacked (de Jong \& Muris, 2002). It seems that, independent of fear, all participants associate spiders with harm-related beliefs. Typically, the high spider fearful group also associates spiders more strongly with disgusting consequences than the low spider fearful group.

The bivariate correlations showed that, in line with a predator-defense explanation for a fear of pit bull terriers, a fear of fierce animals (pit bull terriers) was associated with inflated expectations of harm-related outcomes (shock) on pit bull trials. Fear of maggots was not associated with inflated expectancies of disgust-related outcomes on maggot trials. One testable explanation could be that fear of small animals is mainly determined by the interaction of disgust with the perceived likelihood of involuntary physical contact 
(de Jong \& Muris, 2002). For animals that are virtually universally considered as highly disgusting (e.g., maggots), the variability of fear is mainly determined by the variability in the perceived likelihood of involuntary physical contact. So, since most people consider maggots highly disgusting (as confirmed by the present study), a fear of maggots will be predominantly determined by the perceived probability of involuntary physical contact.

Since spider fearful individuals tend to have higher levels of disgust sensitivity (de Jong, Andrea, \& Muris, 1997; Merckelbach, de Jong, Arntz, \& Schouten, 1993; Mulkens, de Jong, \& Merckelbach, 1996), it was expected that spider fearful individuals would not only associate spiders but also maggots relatively strongly with disgust-relevant outcomes. This was not the case. One explanation might be that people in general associate maggots already strongly with disgusting consequences, such that a ceiling effect prevents disgust sensitivity to further contribute to people's expectancy that maggots will be followed by disgust-relevant outcomes.

For spiders, the results revealed a different pattern. Here, the expectation of disgustrelated consequences following their presentation was significantly stronger in the high spider fearful group compared to the low fearful group. It would be interesting to examine in future research whether this association between spider fear and disgust-relevant outcome expectancies is causal in nature. If indeed disgust-relevant outcomes expectancies are causally related to a fear of spiders, then priming or inflating disgust-relevant outcome representations should enhance the experience of spider fear. Preliminary evidence suggests this might be the case. In a study by Webb and Davey (1992), participants saw either a threat-related movie (i.e., extreme violence) or a disgusting movie (i.e., a surgery), after which they saw a slide show featuring animal slides. They had to rate how afraid they were of each animal. Results showed that participants who saw the threat-related movie were significantly more afraid of predatory animals, and participants who saw the disgusting movie were significantly more afraid of disgusting animals (Webb \& Davey, 1992). A second indication that expectancy bias might be causally involved in spider phobia was found by de Jong, van den Hout, and Merckelbach (1995). They showed that treated spider phobics who showed a residual bias to overestimate the covariation between spiders and harm-relevant outcomes had a relatively large chance of a return of phobic fear complaints after 2 years of follow-up. Results of the present study suggest that a residual expectancy bias toward disgusting consequences might be relevant as well.

The present study even reveals that expectations of disgust-related consequences following spiders are at least equally relevant in spider fear as expectations of harm-related consequences. It is not illogical that spiders are also associated with disgust-relevant consequences. Most spider species known in European countries are completely harmless (Davey, 1994a), and only a very small fraction of all known spiders species do actually possess lethal qualities (Roberts, 1995). However, throughout history, spiders have become linked with the spread of numerous diseases. In 1307 in southern Italy, a strange disease occurred called 'Tarantism' after people were bitten by spiders (Russel, 1979). In the middle ages, spiders became associated with the black plague (de Jong, 1996) and even today, diagnoses of several diseases that follow from a bite by the brown recluse spider greatly outnumber their presence in the USA (Vetter, Cushing, Crawford, \& Royce, 2003). Therefore, it has been suggested that a fear of small animals, such as spiders, can be related better to a disease-avoidance model than a predator-defense model (Matchett \& Davey, 1991). The disease-avoidance model postulates that spiders would be associated with their potential to spread disease, dirt, and contamination. By being disgusted of spiders, people 
would want to avoid physical contact, thus, protecting people against diseases. Spiders would acquire such a disgust-evoking status by means of three possible routes by: (1) directly spreading disease, (2) being contingently associated with dirt or contamination or (3) resembling prototypical disgust stimuli (Davey, 1992a).

The finding that disgust-related expectations can be observed in spider fearful individuals following presentation of a spider not only supports the idea that disgust may contribute to the occurrence of spider phobia, but it may also have important implications for treatment. To make the treatment for spider phobia more successful, it would be advisable to reduce the expectancy bias for both components (expectation of harm-related and disgust-related consequences). This could be done by addressing not only the harm-related beliefs people may hold about spiders, but also their disgust-evoking status as well (de Jong, Vorage, \& van den Hout, 2000).

Finally, some comments are in order with respect to several limitations in the present study. First, the current study used non-clinical participants who displayed an extreme fear of spiders, as measured with the FSQ. Although differences in UCS expectancies were observed between the high and low spider fearful group, the data did not reveal significant differences between harm and disgust expectancies in the high fearful group. Both aversive consequences were expected significantly more often following presentation of a feared stimulus. It could be argued that individuals with clinical levels of spider fear might be more focused on aspects of harm than on the possibility of contamination with a disgusting object. Although the results of the present study are in line with previous research using analog groups (de Jong \& Muris, 2002; de Jong et al., 2002; Woody \& Tolin, 2002), it cannot be ruled out that a treatment-seeking sample will be characterized by a different expectancy bias.

Second, this study has only included female participants. It is known that women tend to have higher levels of disgust sensitivity than men (Davey, 1994b; Ware, Jain, Burgess, \& Davey, 1994). This may have resulted in higher baseline-measurements of expectations of disgust consequences following disgust-relevant animals. It could be that compared to a sample that does have an equal distribution of males and females, the UCS expectations for disgust consequences following spiders in the present study are higher.

Third, it was established that highly spider fearful individuals displayed relatively strong expectancies for both harm and disgust-relevant outcomes following spider slides. Expecting either of these types of consequences may motivate phobics to avoid spiders, and thus, to avoid potentially disconfirming information. However, recently it has been shown that even if people obtain disconfirming information, they still persist in their dysfunctional expectations (de Jong \& Merckelbach, 2000; Pauli, Montoya, \& Martz, 1996, 2001). Therefore, it would be important to examine this relative insensitivity to disconfirming information to determine which of the expectations is most strongly associated with fear of spiders. Hence, it would be interesting to subject both high and low spider fearful individuals to an illusory correlation paradigm including both types of outcomes to examine for both types of expectancy biases the relative (in)sensitivity to corrective information.

Additionally, an implication of the present study could be that an expectancy bias for disgust-related consequences may contribute to the etiology and maintenance of several other disgust-relevant disorders as well, e.g., eating disorders (Troop, Murphy, Bramon, \& Treasure, 2000; Troop, Treasure, \& Serpell, 2002), obsessive-compulsive disorders (Mancini, Gragnani, \& D’Olimpio, 2001; Woody \& Tolin, 2002), and blood phobia 
(Sawchuk et al., 2002). Also, studying expectations of both harm-related and disgustrelated consequences could provide an explanation as to why previous studies found no expectancy bias for these disorders. For instance, in a study by Pury and Mineka (1997), both high and low blood fearful participants overestimated the co-occurrence of a harmrelated consequence following fear-relevant slides. More importantly, no differences were observed between the high and low fearful groups. It could be, that although no expectancy bias for harm-related consequences (the shock) was apparent, an expectancy bias for disgust-related consequences (juice) might well be found.

\section{Acknowledgements}

The authors would like to express their gratitude to Nienke Sweers and Jorg Huijding for their efforts in the process of data collection.

\section{References}

Cavanagh, K., \& Davey, G. C. L. (2000). UCS expectancy biases in spider phobics: Underestimation of aversive consequences following fear-irrelevant stimuli. Behaviour Research and Therapy, 38, 641-651.

Davey, G. C. L. (1992a). An expectancy model of laboratory preparedness effects. Journal of Experimental Psychology, 121, 24-40.

Davey, G. C. L. (1992b). Characteristics of individuals with fear of spiders. Anxiety Research, 4, $299-314$.

Davey, G. C. L. (1994a). The "disgusting" spider: The role of disease and illness in the perpetuation of fear of spiders. Society and Animals, 2, 17-25.

Davey, G. C. L. (1994b). Self-reported fears to common indigenous animals in an adult UK population: The role of disgust sensitivity. British Journal of Psychology, 85, 541-544.

Davey, G. C. L., Cavanagh, K., \& Lamb, A. (2003). Differential aversive outcome expectancies for high- and lowpredation fear-relevant animals. Journal of Behavior Therapy and Experimental Psychiatry, 34, 117-128.

de Jong, P. J. (1996). Walging en spinfobie. Gedragstherapie, 29, 165-179.

de Jong, P. J., Andrea, H., \& Muris, P. (1997). Spider phobia in children: Disgust and fear before and after treatment. Behaviour Research and Therapy, 35, 559-562.

de Jong, P. J., van den Hout, M. A., \& Merckelbach, H. (1995). Covariation bias and the return of fear. Behaviour Research and Therapy, 33, 211-213.

de Jong, P. J., \& Muris, P. (2002). Spider phobia: Interaction of disgust and perceived likelihood of involuntary physical contact. Journal of Anxiety Disorders, 16, 51-65.

de Jong, P. J., Peters, M. L., \& Vanderhallen, I. (2002). Disgust and disgust sensitivity in spider phobia: Facial EMG in response to spider and oral disgust imagery. Journal of Anxiety Disorders, 16, 477-493.

de Jong, P. J., Vorage, I., \& van den Hout, M. A. (2000). Counterconditioning in the treatment of spider phobia: Effects on disgust, fear, and valence. Behaviour Research and Therapy, 38, 1055-1069.

Kennedy, S. J., Rapee, R. M., \& Mazurski, E. J. (1997). Covariation bias for phylogenetic versus ontogenetic fearrelevant stimuli. Behaviour Research and Therapy, 35, 415-422.

Mancini, F., Gragnani, A., \& D'Olimpio (2001). The connection between disgust and obsessions and compulsions in a non-clinical sample. Personality and Individual Differences, 31, 1173-1180.

Matchett, G., \& Davey, G. C. L. (1991). A test of a disease-avoidance model of animal phobias. Behaviour Research and Therapy, 29, 91-94.

McNally, R. J., \& Heatherton, T. F. (1993). Are covariation biases attributable to a priori expectancy biases? Behaviour Research and Therapy, 31, 653-658.

Merckelbach, H., de Jong, P. J., Arntz, A., \& Schouten, E. (1993). The role of evaluative learning and disgust sensitivity in the etiology and treatment of spider phobia. Advances in Behaviour Research and Therapy, 15, $243-255$

Mulkens, S. A. N., de Jong, P. J., \& Merckelbach, H. (1996). Disgust and spider phobia. Journal of Abnormal Psychology, 105, 464-468.

Muris, P., \& Merckelbach, H. (1996). A comparison of two spider fear questionnaires. Journal of Behavioral Therapy and Experimental Psychiatry, 27, 241-244. 
Öhman, A., Dimberg, U., \& Öst, L.-G. (1985). Animal and social phobias: Biological constraints on learned fear responses. In S. Reiss, \& R. R. Bootzin (Eds.), Theoretical issues in behavior therapy (pp. 123-175). New York: Academic Press.

Pauli, P., Montoya, P., \& Martz, G.-E. (1996). Covariation bias in panic-prone individuals. Journal of Abnormal Psychology, 105, 658-662.

Pauli, P., Montoya, P., \& Martz, G.-E. (2001). On-line and a posteriori covariation estimates in panic-prone individuals: Effects of a high contingency of shocks following fear-irrelevant stimuli. Cognitive Therapy and Research, 25, 103-116.

Pauli, P., Wiedemann, G., \& Montoya, P. (1998). Covariation bias in flight phobics. Journal of Anxiety Disorders, $12,555-565$.

Pury, C. L. S., \& Mineka, S. (1997). Covariation bias for blood-injury stimuli and aversive outcomes. Behaviour Research and Therapy, 35, 35-47.

Roberts, M. J. (1995). Spiders of Britain \& Northern Europe. London: HarperCollins Publishers.

Russel, J. F. (1979). Tarantism. Medical History, 23, 404- 425.

Sawchuk, C. N., Lohr, J. M., Tolin, D. F., Lee, T. C., \& Kleinknecht, R. A. (2000). Disgust sensitivity and contamination fears in spider and blood-injection-injury phobias. Behaviour Research and Therapy, 38, 753-762.

Sawchuk, C. N., Lohr, J. M., Westendorf, D. H., Meunier, S. A., \& Tolin, D. F. (2002). Emotional responding to fearful and disgusting stimuli in specific phobia. Behaviour Research and Therapy, 40, 1031-1046.

Szymanski, J., \& O'Donohue (1995). Fear of Spiders Questionnaire. Journal of Behavior Therapy and Experimental Psychiatry, 26, 31-34.

Thorpe, S., \& Salkovskis, P. M. (1998). Studies on the role of disgust in the acquisition and maintenance of specific phobias. Behaviour Research and Therapy, 36, 877-893.

Tolin, D. F., Lohr, J. M., Sawchuk, C. N., \& Lee, T. C. (1997). Disgust and disgust sensitivity in blood-injectioninjury and spider phobia. Behaviour Research and Therapy, 35, 949-953.

Tomarken, A. J., Mineka, S., \& Cook, M. (1989). Fear-relevant selective associations and covariation bias. Journal of Abnormal Psychology, 98, 3381-3394.

Troop, N. A., Murphy, F., Bramon, E., \& Treasure, J. L. (2000). Disgust sensitivity in eating disorders: A preliminary investigation. International Journal of Eating Disorders, 27, 446-451.

Troop, N. A., Treasure, J. L., \& Serpell, L. (2002). A further exploration of disgust in eating disorders. European Eating Disorders Review, 10, 218-226.

Vetter, R. S., Cushing, P. E., Crawford, R. L., \& Royce, L. A. (2003). Diagnoses of brown recluse spider bites (loxoscelism) greatly outnumber actual verifications of the spider in four western American states. Toxicon, 42, 413-418.

Ware, J., Jain, K., Burgess, I., \& Davey, G. C. L. (1994). Disease-avoidance model: Factor analysis of common animal fears. Behaviour Research and Therapy, 32, 57-63.

Webb, K., \& Davey, G. C. L. (1992). Disgust sensitivity and fear of animals: Effect of exposure to violent or repulsive material. Anxiety, Stress and Coping, 5, 329-335.

Wiedemann, G., Pauli, P., \& Dengler, W. (2001). A priori expectancy bias in patients with panic disorder. Journal of Anxiety Disorders, 15, 401-412.

Woody, S. R., \& Tolin, D. F. (2002). The relationship between disgust sensitivity and avoidant behavior: Studies of clinical and nonclinical samples. Journal of Anxiety Disorders, 16, 543-559. 